\title{
IN PRESS COMPUTERS IN HUMAN BEHAVIOR
}

\author{
Paying for loot boxes is linked to problem gambling, regardless of \\ specific features such as cash-out and pay-to-win
}

\begin{abstract}
Loot boxes are items in video games that may be bought with real-world money but contain randomised contents. Due to similarities between loot boxes and gambling, various countries are considering regulating them to reduce gambling-related harm. However, loot boxes are extremely diverse. A key problem facing regulators is determining whether specific types of loot boxes carry more potential for harm, and should be regulated accordingly.

In this study, we specify seven key ways that loot boxes may differ from each other: They may involve paid or unpaid openings; give opportunities for cashing out; allow gamers to pay to win; involve the use of an in-game currency; feature crate and key mechanics; show near misses; and contain exclusive items.
\end{abstract}

We then use a large-scale preregistered correlational analysis $(n=1200)$ to determine if any of these features strengthen the link between loot box spending and problem gambling. Our results indicate that being able to cash out, showing near-misses, and letting players use in-game currency to buy loot boxes may weakly strengthen the relationship between loot box spending and problem gambling. However, our main conclusion is that regardless of the presence or absence of specific features of loot boxes, if they are being sold to players for real-world money, then their purchase is linked to problem gambling.

\section{Introduction}

What are loot boxes?

Loot boxes are items in video games that players may buy for real-world money but have randomised contents. For example, players of Counter-Strike: Global Offensive pay real-world money to open sealed 'weapon cases'. However, when paying this money, they do not know if the case that they are paying to open contains a rare and valuable knife, or something common and almost worthless instead. Similarly, players of Rocket League can pay real-world money to open crates that contain cosmetic 'decals' for their in-game cars. However, when paying to open a crate, players have no way of knowing whether it contains a rare and appealing item, or something else entirely.

Selling loot boxes to players generates enormous amounts of money for the video game industry. One industry report estimates that they may create up to $\$ 30$ billion dollars in revenue in 2018 alone, with this amount estimated to almost double over the next four years [1].

There are distinct similarities between paying for loot boxes and gambling. Both when paying to buy a loot box and when playing blackjack in a casino, individuals stake real-world money in the uncertain hope of receiving a valuable reward. These similarities have raised concerns that loot boxes may either encourage or exploit problem gambling - a pattern of gambling-related behaviour 
which is so disordered and excessive that it leads to problems in a gambler's personal, work, and family life [2].

In a recent comment to Nature: Human Behavior, Drummond and Sauer hypothesise that some kinds of loot boxes share so many features with gambling that they may be considered "psychologically akin to gambling", and provide a gateway for gamers to just that: problem gambling and gambling-related harm [3]. Recent research supports these claims, demonstrating a clear correlation between buying loot boxes and problem gambling. This research has shown that that the more money players spend on loot boxes, the more severe their problem gambling is [4]-[6].

\section{What different kinds of loot boxes exist?}

Loot boxes' potential for gambling-related harm has not been lost on legislators. Sixteen gambling regulators from around the world have recently signed an agreement to investigate the risks associated with loot boxes [7]. The Finnish government is currently carrying out an investigation into the potential for gambling-related harm present in loot boxes [8]. The USA's Federal Trade Commission has recently announced a public workshop on loot boxes[9]. Whilst specific gambling regulations in some territories preclude loot boxes from being regulated as gambling [10], a minority of countries have banned specific loot boxes as gambling: For example, regulators in both the Netherlands and Belgium have determined that certain loot boxes break national gambling laws and ordered their removal from video games [11].

A key problem facing regulators around the world is that loot boxes come in a variety of forms. For example, some loot boxes are paid for with real-world money, whilst others are not. Some loot boxes allow players to trade their contents, and sell them to each other for real-world money, whilst others do not. It is currently unclear which of these kinds of loot boxes might be most harmful to gamers, and it is therefore also unclear which should be regulated. In the words of Jordon SteeleJohn, the chair of the Australian Senate's inquiry into loot boxes and gambling-related harm, this knowledge constitutes the "critical piece of clarifying information" [12] when it comes to the regulation of loot boxes. In the subsections below we detail the following seven important ways that loot boxes may differ from each other:

1. Paid and unpaid openings

2. Opportunities for cashing out

3. Paying to win

4. Using in-game currency

5. Crate and key mechanics

6. Showing near-misses

7. Containing exclusive items.

\section{Paid and unpaid openings}

One of the most important distinctions to make when it comes to loot boxes is their cost. Some loot boxes always cost money to open. For example, players of Counter Strike: Global Offensive cannot open loot boxes without spending actual money. However, many games that contain loot boxes also offer their players the option to take part in so-called 'unpaid openings', where no real-world money is exchanged for the loot box itself. For example, whilst players of Overwatch may choose to pay for loot boxes, they also 'earn' them for playing the game itself: They are rewarded with a loot box each time they level up [13].

Similarly, players of Clash Royale can either buy chests that contain randomised rewards from an ingame shop, or earn them as a reward for winning battles [14]. Furthermore, these chests will either 
open after a set period of time, or their opening can be hastened by paying further real-world money. In the same vein, players of League of Legends can either buy the game's equivalent of loot boxes outright for real-world money, or earn them at a slower rate by achieving high in-game mastery scores [15].

In contrast, other games offer loot boxes that cannot be purchased for real-world money at all. For example, Star Wars: Battlefront II contains loot boxes which cannot be paid for with real-world money under any circumstances. They are instead solely "earned via daily login bonuses, milestone completions, or timed challenges"[16].

It is reasonable to suggest that whether players pay for loot boxes may be one of the most important factors in determining the relationship between loot box purchases and problem gambling. As noted in [17], one of the key features that typically differentiates gambling from other activities is that it involves the exchange of money or valuable goods. Accordingly, The amount that individuals spend on loot boxes has been repeatedly linked to problem gambling in empirical research [4]-[6].

\section{Opportunities for cashing out}

Another major distinction when it comes to loot boxes is the ability to make money from their contents. In some games, the rewards that are gained from loot boxes are bound to a player's account. They cannot be traded or sold to other players. There is no way to make money from these loot boxes short of a player selling their entire account. Examples of games like this are Overwatch and Destiny 2.

However, in strong contrast to this, the contents of loot boxes in some games are not immediately bound to a player's account. This creates the potential for items to be sold to other players - either in return for other in-game items or rewards, or in return for real-world money.

Indeed, some games incorporate the ability to 'cash out' into the game itself. For example, players of Counter Strike: Global Offensive and Player Unknown's Battlegrounds can buy and sell the in-game rewards that they receive from opening loot boxes for real money via these games' integration with the Steam marketplace. Once this money has been made on the Steam marketplace, it can then be spent on other games, or other in-game items.

In many cases, selling loot box items is not built into the game itself, but is still possible via an externally-hosted marketplace. For example, players of Rocket League are not officially able to sell the items that they gain from loot boxes 'in-game'. However, these items are not locked to players' accounts and can therefore be traded between accounts. A variety of external marketplaces have sprung up which take advantage of this ability to buy and sell the contents of loot boxes for realworld money. Sales on these so-called 'grey markets' can be extremely lucrative. Many items can be sold for hundreds, or even thousands of dollars[18].

There are good reasons why the ability to cash out might strengthen relationships between loot box spending and problem gambling. In traditional gambling activities, individuals often wager money in the hopes of receiving a reward that is of greater value. The blackjack player makes their bet in the hopes of increasing their initial stake; the fruit machine gambler puts money in the machine in the hopes of receiving a jackpot. Researchers have pointed out that if loot box contents can be sold for real-world money, then they are mirroring this key feature of gambling [17]. If players can cash out, then, just like the individuals outlined above, gamers can wager real-world money in the hopes of receiving a larger financial reward in the future. 
Indeed, researchers have noted that whether the rewards that loot boxes offer are "embedded" in the real-world's economy may be an important factor in determining their effects[19]. The importance ascribed to the ability to 'cash out' is also reflected in movements to legislate against loot boxes: In Netherlands, for example, only loot boxes that can be sold for real-world money have been deemed gambling and made illegal[20].

Paying to win

In some games, the items that are contained within loot boxes can afford players a distinct advantage when playing the game itself. For example, in Fire Emblem Heroes, stronger units are available in loot boxes than elsewhere in the game. Similarly, players of Hearthstone can obtain powerful cards with unique abilities by opening sealed packs of cards with randomised contents.

By contrast, in many games, loot box contents are purely cosmetic and give no competitive advantage at all. No matter how much money players of these games pay, they cannot pay to increase their likelihood of winning. Examples of games like this include Path of Exile, Overwatch, Rocket League, and Counter Strike: Global Offensive.

Competitiveness is well-known as an important factor when it comes to gambling. Indeed, gambling activities like poker directly tie success in competition to the results of gambles themselves. Not only are competitive individuals more likely to engage in gambling [21], [22], but competitiveness itself has been cited as a risk factor for problem gambling [23]. Tying competitive advantage to loot box rewards may well therefore strengthen the link between problem gambling and loot box spending. Similarly, whilst the loot boxes outlined in previous subsections varied in terms of financial reward, allowing players to 'pay to win' might add additional value to loot box contents, altering their effects on problem gambling.

\section{Using in-Game currency}

In some games, loot boxes are bought directly with real-world currency: For example, in Overwatch and Hearthstone loot boxes can be bought directly for cash.

However, in many more games, loot boxes are not bought directly for real-world money, but are instead paid for using a form of scrip: a 'middleman' in-game currency. This currency may itself be bought directly for real-world money, or earned by players in-game. For example, in Fire Emblem Heroes, players can pay a certain number of 'orbs' for the chance to randomly receive a new character. These orbs can themselves be bought for real-world money.

Paying with scrip is a common feature of gambling activities across the world. Indeed, casino chips represent exactly this. One could speculate that the use of in-game currencies may be linked to gambling-related harm as a product of valuation biases. For example, previous studies have indicated that individuals tend to spend more when they are spending scrip rather than cash [24]. Similarly, poker players have been shown to gamble more money if they are using chips than if they are using cash [25]. It seems possible that these effects might influence players to spend in a disordered fashion when using in-game currency.

\section{Crate and key mechanics}

The loot boxes in some games are built around a 'crate and key' mechanic. In this system, players typically earn loot boxes themselves through the course of playing the game but must obtain a key in order to open these boxes. Obtaining a key usually involves the transfer of real-world money.

For example, in Star Trek Online, loot boxes are earned by players as a reward for defeating in-game enemies. However, in order to open a loot box, players require a 'master key'. These keys can be 
bought from an in-game exchange for real-world money. Similarly, in Counter Strike: Global Offensive, players can obtain loot boxes as 'random drops' from playing the game itself. However, the keys that are required to open these loot boxes must either be purchased for real-world money via an in-game store or traded for with other players.

There are various reasons why the presence of crate and key systems might strengthen the effects of loot box spending on problem gambling. One example of this is sunk cost effects. The sunk cost effect is "a greater tendency to continue an endeavor once an investment in money, effort, or time has been made"[26]. Sunk cost effects are thought to be key to the psychology of gambling[27] and are often used to explain why individuals continue gambling even after large losses have been made [28]. If players perceive that they have already made an investment of money or time to acquire a loot box, they may be more likely to try to open it due to their attempt to recoup this sunk cost.

Crate and key systems might also capitalize on illusions of control, false beliefs that one is some way in control of chance outcomes [29]. Much research has suggested that illusions of control play an important role in traditional gambling (e.g. [30], [31]).

Some of these illusions may be the consequence of allowing players to feel as if their own skill allows them to control the results of a gamble. For example, in [32], researchers suggest that the presence of special interactive features in fruit machines may create an illusion of control in which players feel as if their own skill with the machine determines the success of their gambling. Similarly, a players' perception that their skill has earned them a crate and key loot box might make them feel in greater control of the results of their loot box purchasing, which in turn might impact spending on these items. Indeed, similar effects to these have been posited in the literature on fruit machine gambling

Showing near-misses

A further key distinction to make between different kinds of loot boxes is whether they show 'near misses' or not. Some loot boxes - for instance, those in Path of Exile - simply show players the contents of a loot box after they have opened it. However, others show players a variety of rare items that players might have won by opening that loot box. Typically, this display implies that players have almost received these valuable items from opening the loot box - in other words, that they are 'near misses'. For example, when opening loot boxes in DOTA 2, players are shown a spread of spinning rewards of varying rarity. These rewards gradually disappear over time, until only a single, more likely less valuable, reward remains. Often, the very last rewards to disappear are extremely rare. Similarly, Counter Strike: Global Offensive shows players a spinning, roulette-wheellike reel of various items. This reel gradually slows over time until it eventually stops. The item in the centre of the screen at this point is received by the centre - but often a rare item is displayed right next to it.

Near-misses feature in a variety of different kinds of gambling. For example, slot machine designers deliberately include mechanisms in their machines where players who have lost are deliberately shown 'losing' combinations of symbols that are close to those required to win large amounts[33].

Research on gambling demonstrates that near-misses in games of chance lead to cognitive distortions whereby the player believes they are more likely to win in the future [34]. Players are more likely to continue taking risks after a near-miss [35], [36]. Furthermore, near-misses may be particularly potent for problem gamblers, who show distinct patterns in neural activity in rewardrelated brain regions and who may consequently show enhanced motivation to gamble (for review, see [30]). It therefore seems possible that the presence of near misses in loot boxes might strengthen the relationship between loot box spending and problem gambling. 


\section{Containing exclusive items}

Most loot boxes contain exclusive items - things that can be found in loot boxes and nowhere else in the game. For example, loot boxes in Counter Strike: Global Offensive and Rocket League contain unique cosmetic items. These items only appear in loot boxes and can only be obtained by either opening a loot box or by trading with another player for the contents of a loot box that they have opened.

However, this is not the case in all games. In some games, loot boxes contain items that are obtainable elsewhere in game. Often these items can be directly purchased using an in-game currency. For example, in Path of Exile, 1 month after a loot box is released, all possible items within that loot box become available for direct purchase via an in-game store.

As noted above, loot boxes can be associated with both financial and competitive value. However, it seems reasonable that the worth of loot boxes is not only bound to these dimensions. Loot boxes also contain content that carries significant value within the world of the game. The value of some loot boxes quite possibly lies in the fact that their content isn't available anywhere else in the game.

\section{Problem gambling}

As noted in [37], new technologies can open up new opportunities for gambling, and, hence, the development of problem gambling. Due to similarities between loot boxes and gambling, there is concern that loot boxes may act as a 'gateway' to other gambling activities, and thereby cause problem gambling amongst gamers [3].

Problem gambling refers to a disordered and excessive involvement in gambling activities that is so extreme it leads to significant negative consequences for the gambler, both in their personal, family, financial, and professional lives. For example, problem gamblers may bet more than they can afford to lose; lie to family members in order to hide their gambling; feel unable to quit gambling; and borrow money in order to continue gambling [38]. Problem gambling is associated with factors like drug abuse, depression, and alcoholism[39] and is well-known to be linked to severe negative social and health-related consequences (e.g. [40], [41]), as well as more obvious financial consequences such as credit card debt, bank loans, illegal debts with bookmakers[42], and bankruptcy[43].

Problem gambling is notedly heterogenous, and as such there is no such thing as a 'typical' problem gambler [2]. There is furthermore no single route by which problem gambling may be conclusively said to develop. In [2], Blasczynski and Nower put forth the widely-cited 'pathways model' of problem gambling. The pathways model proposes that there are several elements that "major pathways" to problem gambling have in common. More specifically, it proposes that the starting point for problem gambling usually lies with the "availability and access to gambling". Once gambling has been made available, the development of problem gambling continues via processes of classical and operant conditioning; uncertain patterns of reward common in gambling activities lead to the development of habitual gambling behaviours via processes of reinforcement. Thirdly, Blascznyski and Nower argue that this habitual engagement in gambling leads to the development of biased cognitive schemas such as the 'gamblers fallacy', resulting ultimately in problem gambling behaviour.

Arguments that propose a link between loot box spending and problem gambling may be justified by the model given above. Problem gambling is thought to ultimately be a consequence of an initial availability of gambling. If loot boxes share so many similarities with gambling that they may be considered "psychologically akin"[3] to gambling, then it is plausible that the availability of loot boxes leads to subsequent problem gambling: Individuals engage in spending on loot boxes, which 
leads to processes of classical and operant conditioning. This ultimately culminates in the development of biased cognitive schemas and the development of problem gambling.

However, it is important to note that any links between problem gambling and loot box spending seen in the literature (e.g. [6], [44]) may represent a different causal relationship entirely. Because of similarities between loot boxes and gambling, disordered and excessive spending on gambling activities amongst problem gamblers may transfer to disordered and excessive spending on loot boxes. Thus, loot box spending may be linked to problem gambling, not because loot boxes cause problem gambling - but because problem gamblers tend to spend more money on loot boxes. This potential causal relationship nevertheless raises further regulatory questions regarding whether or not video games should encourage and capitalize on problem-gamblers' self-destructive behaviour.

\section{Measurement of problem gambling}

One of the most common ways to measure problem gambling in the literature is the Problem Gambling Severity Index (PGSI) [38]. This nine-item instrument has been extensively validated (e.g. [45]-[47]). It has been used to measure problem gambling in a variety of studies (e.g. [48]-[50]).

The PGSI contains a series of questions about how frequently individuals have engaged in a variety of gambling-related behaviours in the past 12 months (e.g. 'Have you needed to gamble with larger amounts of money to get the same feeling of excitement?', 'Have you borrowed money or sold anything to get money to gamble?'). Individuals must indicate how frequently they engage in these activities on a four-point scale ranging from 'Never' to 'Almost Always'. These responses are each scored from $0-3$, with their sum forming a total score ranging from 0 to 27 . Cut-offs for these scores, proposed in [45], diagnose problem gambling as a score of 8 or more, with a score of 0 representing a 'non problem gambler', a score of 1-4 representing a 'low risk gambler', and a score of 5-7 representing a 'moderate risk gambler'.

\section{Hypotheses}

This study involves the preregistered testing of 13 specific hypotheses about the relationship between loot box spending and problem gambling (as measured by the PGSI). The preregistration details for these hypotheses (and all other details of this study) are available at [51]. These hypotheses (and their preregistered analysis plan) are presented below.

\section{Hypotheses that relate to paid and unpaid openings of loot boxes}

As described above, previous research has repeatedly linked spending on loot boxes to problem gambling. The more individuals spent on loot boxes, the more severe their problem gambling was. Therefore, we hypothesise the following:

H1. There will be a significant positive correlation between the extent of an individual's problem gambling and their spending on loot boxes.

H2. There will be a significant relationship between whether a player pays for loot boxes or engages only in unpaid openings and their problem gambling.

\section{Hypotheses that relate to cashing out}

As described above, some games allow players to 'cash out', and exchange the items that they win from loot boxes for real world money. There is concern that these loot boxes may be especially harmful, as they share more formal features with gambling than other loot boxes. Therefore, we hypothesise the following:

H3. Being able to cash-out in an in-game marketplace will strengthen the relationship between loot box spending and problem gambling. 
H4. Being able to cash-out in an externally-hosted marketplace will strengthen the relationship between loot box spending and problem gambling.

H5. Being able to cash out in either an in-game marketplace OR an externally-hosted marketplace will strengthen the relationship between loot box spending and problem gambling.

H6. The ability to trade loot box items in a video game will strengthen the relationship between loot box spending and problem gambling.

H7. Making money by selling loot box items will strengthen the relationship between loot box spending and problem gambling.

H8. There will be a significant positive correlation between the extent of an individual's problem gambling and the amount of money they make by selling loot box items.

\section{Hypotheses that relate to paying to win}

Some loot boxes contain items that may give players a competitive gameplay advantage. Competitiveness is a common feature in many forms of gambling, and is thought to be a risk factor in the development of problem gambling. Therefore, we hypothesise the following:

H9. Being able to use lootbox contents for gameplay advantages will strengthen the relationship between loot box spending and problem gambling.

Hypotheses that relate to near misses

Some loot boxes show 'near misses' to players of items that they could have won, but did not. Near miss effects have been linked to a variety of cognitive distortions during gambling. Therefore, we hypothesise the following:

H10. Showing near-misses will strengthen the relationship between loot box spending and problem gambling.

Hypotheses that relate to in-game currency

Some loot boxes allow players to buy loot boxes with a 'middleman' in-game currency. Previous studies have shown that the use of scrip during gambling leads to valuation biases amongst gamblers. Therefore, we hypothesise the following:

H11. Being able to use-in game currency to buy loot boxes will strengthen the relationship between loot box spending and problem gambling.

Hypotheses that relate to crate and key mechanics

Some games do not sell loot boxes to players directly, but rather sell them some form of key to open sealed boxes or other items that they have acquired during gameplay. This may lead to sunk cost effects or the illusion of control. Therefore, we hypothesis the following:

H12. The presence of crate and key mechanics will strengthen the relationship between loot box spending and problem gambling.

Hypotheses that relate to exclusive items

Some games feature items in loot boxes that are exclusive, cannot be purchased anywhere else in the game, and therefore may be thought of as extremely valuable. Gambling involves wagering something of value in the hopes of receiving something else of perceived greater value. Therefore, we hypothesis the following:

H13. The presence of exclusive items in loot boxes will strengthen the relationship between loot box spending and problem gambling. 


\section{Summary}

It should be clear from the above discussion that some loot boxes may plausibly be more related to problem gambling than others. However, it is not clear from extent research which features are worth further research or regulation. Accordingly, we conducted a preregistered, empirical study. Our first goal was to replicate prior findings that people who purchase loot boxes are more likely to score high on a measure of problem gambling behaviour [5], [6]. We then sought to extend those findings by exploring the moderating relationship of each of the abovementioned factors on this relationship.

\section{Method}

Design

We conducted an online survey via Amazon Mechanical Turk. Participants were recruited with an advertisement that asked them to answer a survey about their spending habits in games. The recruitment message did not mention loot boxes.

Participants were screened before beginning the survey to ensure that they have previously been involved with loot boxes. They were therefore asked the following Yes/No question: "Have you opened a loot box in a video game within the past month?". Only those who answered 'Yes' were able to proceed with the survey.

Participants were then asked a series of questions regarding their loot box spending and problem gambling. Ten of these questions were repeated at the end of the study in order to check that participants were giving reliable answers. Participants who answered more than one of these questions differently were screened out from the sample as unreliable. Screening questions are marked in the list of variables measured below with an asterisk $\left({ }^{*}\right)$.

In order to maximise the reproducibility of this research, a facsimile of the full survey is available to take part in at [52].

\section{Variables}

At the beginning of the survey, players were asked "Over the past month, which game have you most frequently opened loot boxes in?"*. The text result of this question was stored as a string named \$GAME, which was used in several further questions described below. The variables that were then were measured during the survey in order to carry the confirmatory analyses are described below as Table 1.

\begin{tabular}{|c|c|l|}
\hline $\begin{array}{c}\text { Variable } \\
\text { identifier }\end{array}$ & Variable name & \multicolumn{1}{c|}{ Measurement } \\
\hline Var1 & Problem gambling & $\begin{array}{l}\text { Measured via the Problem Gambling Severity Index } \\
\text { (PGSI) [38]. Participants were presented with the items } \\
\text { from the PGSI within a larger series of questions. They } \\
\text { were informed that this series of questions related to } \\
\text { impulsiveness }\end{array}$ \\
\hline
\end{tabular}




\begin{tabular}{|c|c|c|}
\hline \multicolumn{3}{|c|}{ Variables that relate to paid and unpaid openings } \\
\hline Var2 & $\begin{array}{c}\text { Whether a player pays for } \\
\text { loot boxes }\end{array}$ & $\begin{array}{l}\text { The following question was asked to players, with two } \\
\text { possible responses (No/Yes): "Thinking about \$GAME, } \\
\text { have you paid real-world money for opening loot boxes } \\
\text { over the past month? This includes paying real world } \\
\text { money for an in-game currency that is used to buy loot } \\
\text { boxes, or paying real-world money for a key that is used } \\
\text { to open loot boxes." }\end{array}$ \\
\hline Var3 & $\begin{array}{l}\text { How much money players } \\
\text { spend on loot boxes }\end{array}$ & $\begin{array}{l}\text { The following question was asked to players, with a free } \\
\text { numeric response: "Thinking about \$GAME, how much } \\
\text { money have you paid for loot boxes during the past } \\
\text { month? This includes paying real world money for an in- } \\
\text { game currency that is used to buy loot boxes, or paying } \\
\text { real-world money for a key that is used to open loot } \\
\text { boxes (If you have not paid any money for loot boxes, } \\
\text { just put 0)". }\end{array}$ \\
\hline \multicolumn{3}{|c|}{ Variables that relate to cash out } \\
\hline Var4 & $\begin{array}{l}\text { Being able to cash out via } \\
\text { an in-game marketplace* }\end{array}$ & $\begin{array}{l}\text { The following Yes/No question was asked to players: "In } \\
\text { \$GAME, can the contents of loot boxes be sold on an in- } \\
\text { game marketplace?" }\end{array}$ \\
\hline Var5 & $\begin{array}{l}\text { Being able to cash out via } \\
\text { an externally-hosted } \\
\text { marketplace* }\end{array}$ & $\begin{array}{l}\text { The following Yes/No question was asked to players: "In } \\
\text { \$GAME, can the contents of loot boxes be sold on an } \\
\text { externally-hosted marketplace? }\end{array}$ \\
\hline Var6 & $\begin{array}{l}\text { Being able to cash out via } \\
\text { an in-game marketplace } \\
\text { OR an externally hosted } \\
\text { marketplace }\end{array}$ & $\begin{array}{l}\text { It is important to note that this variable is not measured } \\
\text { by asking an additional question. Instead, Var6 is } \\
\text { calculated as "Yes" if either Var4 OR Var5 have been } \\
\text { answered "Yes". Otherwise, Var6 is calculated as "No". }\end{array}$ \\
\hline Var7 & $\begin{array}{l}\text { Being able to trade loot } \\
\text { box items with other } \\
\text { players in-game* }\end{array}$ & $\begin{array}{l}\text { The following Yes/No question was asked to players: "In } \\
\$ \text { GAME, can you trade any of the items that you get in } \\
\text { loot boxes with other players, instead of them all being } \\
\text { bound to your account?" }\end{array}$ \\
\hline Var8 & $\begin{array}{l}\text { How much money players } \\
\text { make from selling loot } \\
\text { boxes }\end{array}$ & $\begin{array}{l}\text { Players were asked the following question, with a free } \\
\text { numeric response: "How much money have you made by } \\
\text { selling items from loot boxes during the past month? (If } \\
\text { you have not made any money by selling loot boxes, just } \\
\text { put 0). Please give your answer in US Dollars.". }\end{array}$ \\
\hline \multicolumn{3}{|c|}{ Variables that relate to paying to win } \\
\hline
\end{tabular}




\begin{tabular}{|c|c|c|}
\hline Var9 & $\begin{array}{l}\text { Being able to use loot box } \\
\text { contents for a gameplay } \\
\text { advantage }\end{array}$ & $\begin{array}{l}\text { The following Yes/No question was asked to players: "In } \\
\text { \$GAME, can the contents of loot boxes give you a } \\
\text { gameplay advantage?" }\end{array}$ \\
\hline \multicolumn{3}{|c|}{ Variables that relate to near misses } \\
\hline Var10 & $\begin{array}{l}\text { Showing near-misses } \\
\text { when buying loot boxes* }\end{array}$ & $\begin{array}{l}\text { The following Yes/No question was asked to players: "In } \\
\$ \text { GAME, are you shown 'near-misses' of rare items that } \\
\text { you theoretically could have won (e.g. on a roulette } \\
\text { wheel)?" }\end{array}$ \\
\hline \multicolumn{3}{|c|}{ Variables that relate to in-game currency } \\
\hline Var11 & $\begin{array}{l}\text { Being able to use in-game } \\
\text { currency to buy loot } \\
\text { boxes* }\end{array}$ & $\begin{array}{l}\text { The following Yes/No question was asked to players: "In } \\
\text { \$GAME, can you only buy loot boxes with an in-game } \\
\text { currency (e.g. gems, shards)?" }\end{array}$ \\
\hline \multicolumn{3}{|c|}{ Variables that relate to crate and key mechanics } \\
\hline Var12 & $\begin{array}{l}\text { The presence of 'crate and } \\
\text { key' mechanics when } \\
\text { buying loot boxes* }\end{array}$ & $\begin{array}{l}\text { The following Yes/No question was asked to players: } \\
\text { "Does \$GAME feature a 'crate and key' system, where a } \\
\text { key is necessary in order to open a loot box?" }\end{array}$ \\
\hline \multicolumn{3}{|c|}{ Variables that relate to exclusive items } \\
\hline Var13 & $\begin{array}{l}\text { The presence of exclusive } \\
\text { items when buying loot } \\
\text { boxes* }\end{array}$ & $\begin{array}{l}\text { The following Yes/No question was asked to players: } \\
\text { "Does \$GAME feature items in its loot boxes that cannot } \\
\text { be bought or found anywhere else in the game?" }\end{array}$ \\
\hline
\end{tabular}

Table 1: Details of all preregistered variables for confirmatory analyses.

\section{Participants}

As documented in the preregistration information for this study [51], participants were recruited incrementally until there were exactly 1200 valid responses to the survey overall.

1607 full responses were collected in total from Amazon Mechanical Turk workers. Of these 1607, 329 were removed from the sample as unreliable due to answering more than 1 of the 10 screening questions inconsistently. 1 participant listed their age as '1987' and was removed from the sample as non-serious. A further 74 participants did not list a recognisable game when asked which game they had opened loot boxes in within the last month and were removed from the sample (example responses include 'Video game', 'yes', 'foot ball', and '6'). This left 1203 responses overall, of which chronologically the first 1200 were taken.

729 participants (60.8\%) described themselves as male and 445 as female (37.1\%). 237 participants (19.8\%) were aged 18-24; 328 (27.3\%) were aged 25-29; 302 (25.2\%) were aged 30-34; 161 (13.3\%) were aged 35-39; and 173 (14.4\%) were aged 40 or over.

596 participants (50.9\%) were classified as non problem gamblers according to Currie et al.'s revised scoring scheme for the PGSI [45]. A further 313 participants (26.7\%) were classified as low risk of problem gambling. 56 participants $(4.6 \%)$ were classified as moderate risk of problem gambling. 207 participants $(17.7 \%)$ were classified as problem gamblers. 
Analysis plan

$\mathbf{H 1}$ and $\mathbf{H} \mathbf{8}$ were tested via Spearman Rank Correlation analysis. $\mathbf{H} \mathbf{2}$ were tested via the MannWhitney $U$ test. All of these tests were conducted in SPSS.

H3-H13 (Excluding H8) were tested via moderation analysis. Specific details of this analysis are given below. Moderation analysis was run using PROCESS v3 for SPSS, and conducted according to [53]. Moderation was conducted under PROCESS Model 1, with X=Var3 (How much money players spend on loot boxes), and $\mathrm{Y}=$ Var1(Problem gambling) in each case. The moderating variable under test, $\mathrm{W}$, varied for each analysis. However, in each case, when relevant, 'Yes' was coded as 1 and No was coded as 0 . The prevalence of each moderating variable in our sample is described in the Results section below as Table 3. A positive coefficient for $b_{3}$ is predicted in each case (i.e. the moderating variable increasing the strength of the relationship between loot box spending and problem gambling). Each moderation analysis were conducted with 10,000 bootstrap samples.

In total, 13 analyses are undertaken in this study. For additional stringency we subjected all results of these tests to Bonferroni corrections for the testing of 13 hypotheses (i.e. $p<0.05 / 13$, or $p<0.0038)$

\section{Transformations}

As detailed in the preregistration document, Var3 (How much money players spend on loot boxes) and Var8 (How much money players make from selling loot boxes) were rank transformed prior to the analysis of results.

Previous datasets that investigate related issues (e.g. [54]) have featured extreme outliers when it comes to spending - for instance, individuals who claim to spend upwards of $\$ 2000$ a month on loot boxes. To mitigate the effects of these datapoints on our inferences, rank transformation was therefore applied prior to analysis. This transformation was preregistered.

There were 58 unique ranked values for player spending, ranging from \$0 (Rank 1) to \$1500 (Rank 58). There were 51 unique ranked values for how much money players made by selling loot boxes, ranging from $\$ 0$ (Rank 1 ) to $\$ 1500$ (Rank 50). Furthermore, one individual indicated that they earned a purported $\$ 1,000,000$ (Rank 51).

Results

All hypotheses were tested according to our preregistered analysis plan, available at [51]. A detailed description of each of the statistical tests that were used is available in the method above, under the subsection entitled 'Analysis plan'.

Is problem gambling linked to loot box spending?

First, $\mathbf{H 1}$ ("There will be a significant positive correlation between the extent of an individual's problem gambling and their spending on loot boxes") was tested via calculating the Spearman Rank Correlation between Var1 (Problem gambling) and Var3 (How much a player spends on loot boxes). Results indicated a significant positive correlation between loot box spending and problem gambling, supporting H1, $p<0.001$, Spearman's Rho $=0.304$, equivalent to $\eta^{2}=0.092$.

Next, H2 ("There will be a significant relationship between whether a player pays for loot boxes and their problem gambling") was tested via a Mann-Whitney $U$ test, with Var2 (Whether a player pays for loot boxes, coded as Yes/No) as a quasi-independent variable, and Var1 (problem gambling) as dependent variable. 
Results indicated a significant relationship between paying for loot boxes and problem gambling, supporting H2, $\left(U=122117, p<0.001, \eta^{2}=0.60\right)$, with individuals who did not pay for loot boxes having a lower median rank, and mean rank for problem gambling than those who did. A bar-chart showing this relationship is depicted below as Figure 1 . Means and $95 \%$ confidence intervals between groups is depicted below as Table 2 .

\begin{tabular}{|c|c|c|}
\hline Loot box purchasing behaviour & Problem gambling severity & $\mathbf{N}$ \\
\hline $\begin{array}{c}\text { Gamers who only engage in } \\
\text { unpaid openings }\end{array}$ & 2.190 & 451 \\
\hline Gamers who pay to open & $(95 \% \mathrm{Cl}: 1.789-2.591)$ & \\
\hline Total & 5.407 & 749 \\
& $(95 \% \mathrm{Cl}: 4.914-5.899)$ & 1200 \\
\hline
\end{tabular}

Table 2: Means and 95\% Confidence Intervals of problem gambling, split by whether gamers pay to open loot boxes

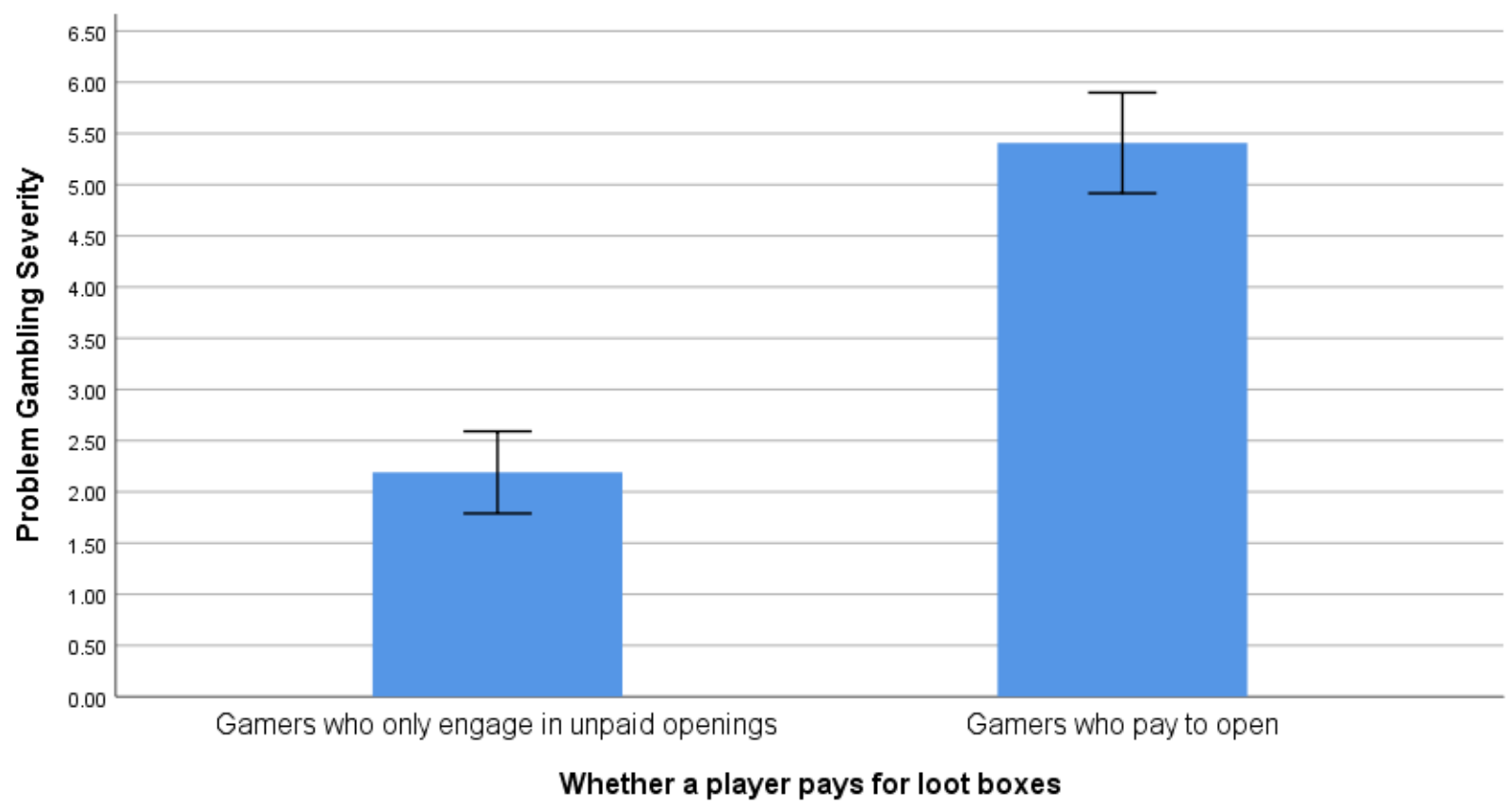

Error Bars: $95 \% \mathrm{Cl}$

Figure 1: Problem gambling severity of gamers, split by whether they pay for loot boxes

Moderation analysis for all below analyses were run using PROCESS v3 for SPSS, and conducted according to [53]. Frequency counts for the proposed moderating factors are given below as Table 3 .

\begin{tabular}{|c|c|c|c|}
\hline \multirow{2}{*}{ Factor } & Variable & $\begin{array}{c}\text { Number } \\
\text { of times } \\
\text { variable } \\
\text { absent }\end{array}$ & $\begin{array}{c}\text { Number } \\
\text { of times } \\
\text { variable } \\
\text { present }\end{array}$ \\
\hline \multirow{2}{*}{ Cash out } & (being able to cash out via an in-game marketplace) & 673 & 527 \\
\cline { 2 - 4 } & Var5 & 857 & 343 \\
\hline
\end{tabular}




\begin{tabular}{|c|c|c|c|}
\hline & $\begin{array}{c}\text { (being able to cash out via an externally-hosted } \\
\text { marketplace) }\end{array}$ & & \\
\hline & $\begin{array}{c}\text { Var6 } \\
\text { (Being able to cash out via an in-game OR externally- } \\
\text { hosted marketplace) }\end{array}$ & 617 & 583 \\
\hline & $\begin{array}{c}\text { Var7 } \\
\text { (being able to trade loot box items with other players) }\end{array}$ & 743 & 457 \\
\hline Paying to win & $\begin{array}{c}\text { Var9 } \\
\text { (being able to use loot box contents for a gameplay } \\
\text { advantage) }\end{array}$ & 387 & 813 \\
\hline Near-misses & $\begin{array}{c}\text { Var10 } \\
\text { (showing near-misses when buying loot boxes) }\end{array}$ & 794 & 406 \\
\hline $\begin{array}{l}\text { In-game } \\
\text { currency }\end{array}$ & $\begin{array}{c}\text { Var11 } \\
\text { (Being able to use in-game currency to buy loot boxes) }\end{array}$ & 540 & 660 \\
\hline Crate and key & $\begin{array}{c}\text { Var12 } \\
\text { (the presence of 'crate and key' mechanics) }\end{array}$ & 673 & 527 \\
\hline $\begin{array}{l}\text { Exclusive } \\
\text { items }\end{array}$ & $\begin{array}{c}\text { Var13 } \\
\text { (the presence of exclusive items) }\end{array}$ & 281 & 919 \\
\hline
\end{tabular}

Table 3: Frequency of moderating features within sample

\section{Is the link between problem gambling and loot box spending moderated by cashing out?}

H3-H7 tested whether being able to cash out in some way strengthened links between loot box spending and problem gambling. Overall, all moderation effects for cash out were significant at the p $<0.0038$ level. Spotlight analyses for $\mathbf{H 3 - 6}$ revealed that these effects were in the hypothesised (i.e. strengthening) direction. However, spotlight analysis for $\mathbf{H} \mathbf{7}$ revealed that, contrary to our predictions, the amount of money that players made from selling loot box items did not strengthen links between problem gambling and loot box spending, but weaken them.

\begin{tabular}{|c|c|c|c|}
\hline Hypothesis under test & $\begin{array}{l}\text { Moderating } \\
\text { effect of } X * W \\
\text { on } Y\end{array}$ & $\begin{array}{l}\text { Effect of } X \text { on } \\
Y \text { when } W= \\
0\end{array}$ & $\begin{array}{l}\text { Effect of } X \text { on } \\
Y \text { when } W= \\
1\end{array}$ \\
\hline $\begin{array}{l}\text { H3: Being able to cash out via an in-game } \\
\text { marketplace strengthens the link between loot } \\
\text { box spending and problem gambling }\end{array}$ & $\begin{array}{c}b_{3}=0.086 \\
t(1196)=4.003 \\
r^{2} \text { change }= \\
0.011, p<0.001^{*}\end{array}$ & $\begin{array}{c}0.052 \\
t=3.497 \\
p<0.001^{*}\end{array}$ & $\begin{array}{c}0.139 \\
t=8.954 \\
p<0.001^{*}\end{array}$ \\
\hline $\begin{array}{l}\text { H4: Being able to cash out via an externally- } \\
\text { hosted marketplace strengthens the link } \\
\text { between loot box spending and problem } \\
\text { gambling }\end{array}$ & $\begin{array}{c}\mathrm{b}_{3}=0.049 \\
\mathrm{t}(1196)=2.099, \\
\mathrm{r}^{2} \text { change }= \\
0.002 \\
\mathrm{p}=0.036^{*}\end{array}$ & $\begin{array}{c}0.063 \\
t=5.003 \\
p<0.001\end{array}$ & $\begin{array}{c}0.112 \\
t=5.701 \\
p<0.001^{*}\end{array}$ \\
\hline $\begin{array}{l}\text { H5: Being able to cash out via an in-game } \\
\text { marketplace OR an externally-hosted } \\
\text { marketplace strengthens the link between loot } \\
\text { box spending and problem gambling }\end{array}$ & $\begin{array}{c}b_{3}=0.084 \\
t(1196)=3.870 \\
r^{2} \text { change }= \\
0.010 \\
p<0.001^{*}\end{array}$ & $\begin{array}{l}0.052 \\
t=3.302 \\
p<0.001^{*}\end{array}$ & $\begin{array}{c}0.137 \\
t=9.149 \\
p<0.001^{*}\end{array}$ \\
\hline $\begin{array}{c}\text { H6: Being able to trade items with other } \\
\text { players strengthens the link between loot box } \\
\text { spending and problem gambling }\end{array}$ & $\begin{array}{c}b_{3}=0.090 \\
t(1196)=4.146\end{array}$ & $\begin{array}{c}0.060 \\
t=4.261 \\
p<0.001^{*}\end{array}$ & $\begin{array}{c}0.150 \\
t=9.036 \\
p<0.001^{*}\end{array}$ \\
\hline
\end{tabular}




\begin{tabular}{|c|c|c|c|}
\hline & $\begin{array}{c}\mathrm{r}^{2} \text { change } \\
0.011 \\
\mathrm{p}<0.001^{*}\end{array}$ & & \\
& $\mathrm{~b}_{3}=-0.005$ & & \\
\hline & $\mathrm{t}(1196)=-4.188$ & 0.063 & 0.058 \\
H7: The amount of money made from selling & $\mathrm{r}^{2}$ change $=$ & $\mathrm{t}=5.541$ & $\mathrm{t}=5.226$ \\
loot box items strengthens the link between & 0.010 & $\mathrm{p}<0.001^{*}$ & $\mathrm{p}<0.001^{*}$ \\
loot box spending and problem gambling & $p<0.001^{*}$ & & \\
\hline
\end{tabular}

Table 4: Moderation analyses investigating the strengthening effects of cash out on links between problem gambling and loot box spending. Results that are significant at the $p<0.0038$ level are marked *

H8 ("There will be a significant positive correlation between the extent of an individual's problem gambling and the amount of money they make by selling loot box items.") was tested via calculating the Spearman Rank Correlation between Var1 (Problem gambling) and Var8 (How much money players make from selling loot boxes). Results indicated a significant positive correlation between loot box spending and problem gambling, supporting H8, $p<0.001$, Spearman's Rho $=0.460$, equivalent to $\eta^{2}=0.211$.

Is the link between problem gambling and loot box spending moderated by paying to win? H9 tested whether being able to use loot box contents for gameplay advantages ('paying to win') strengthened links between loot box spending and problem gambling.

Results indicated that being able to use loot box contents for gameplay advantage did not significantly moderate the relationship between loot box spending and problem gambling, $\left(b_{3}=\right.$ $0.069, t(1196)=2.855, r^{2}$ change $\left.=0.006, p=0.0044\right)$.

Spotlight analyses revealed that loot box spending remained significantly linked to problem gambling both when the moderating variable was absent $(0.065, t=3.168, p<0.001)$ and when it was present $(0.134, t=10.42 p<0.001)$

\section{Is the link between problem gambling and loot box spending moderated by the presence of near misses?}

H10 tested whether showing near-misses when buying loot boxes strengthened links between loot box spending and problem gambling.

Results indicated that showing near-misses significantly strengthened the relationship between loot box spending and problem gambling, $\left(b_{3}=0.064, t(1196)=2.902, r^{2}\right.$ change $\left.=0.005, p=0.0038\right)$.

Spotlight analyses revealed that loot box spending remained significantly linked to problem gambling both when the moderating variable was absent $(0.065, t=4.871, p<0.001)$ and when it was present $(0.129, \mathrm{t}=7.39 \mathrm{p}<0.001)$

\section{Is the link between problem gambling and loot box spending moderated by being able to use in-game currency?}

H11 tested whether being able to use in-game currency to buy loot boxes strengthened links between loot box spending and problem gambling.

Results indicated that being able to use in-game currency significantly strengthened the relationship between loot box spending and problem gambling $\left(b_{3}=0.068, t(1196)=3.08, r^{2}\right.$ change $=0.006$, $\mathrm{p}=0.002)$. 
Spotlight analyses revealed that loot box spending remained significantly linked to problem gambling both when the moderating variable was absent $(0.072, t=4.279, p<0.001)$ and when it was present $(0.141, t=10.015, p<0.001)$

\section{Is the link between problem gambling and loot box spending moderated by the presence of crate and key mechanics?}

H12 tested whether the presence of crate and key mechanics strengthened links between loot box spending and problem gambling.

Results indicated that the presence of crate and key mechanics did not significantly strengthen the relationship between loot box spending and problem gambling $\left(b_{3}=0.040, t(1196)=1.877, r^{2}\right.$ change $=0.002, p=0.06$ ).

Spotlight analyses revealed that loot box spending remained significantly linked to problem gambling both when the moderating variable was absent $(0.084, t=5.729, p<0.001)$ and when it was present $(0.125, t=7.949, p<0.001)$

\section{Is the link between problem gambling and loot box spending moderated by the presence of exclusive items?}

H13 tested whether the presence of exclusive items strengthened links between loot box spending and problem gambling.

Results indicated that the presence of exclusive items did not significantly strengthen the relationship between loot box spending and problem gambling $\left(b_{3}=0.008, t(1196)=0.310, r^{2}\right.$ change $=0.0001, \mathrm{p}=0.756$ ).

Spotlight analyses revealed that loot box spending remained significantly linked to problem gambling both when the moderating variable was absent $(0.114, t=4.890, p<0.001)$ and when it was present $(0.122, t=9.773, p<0.001)$.

\section{Discussion}

The relationship between loot box spending and problem gambling

The results presented here provide more evidence for a link between loot box spending and problem gambling (H1). Preregistered correlational analyses showed that the greater the level of an individual's spending on loot boxes, the more severe their problem gambling. Furthermore, the effect size associated with this relationship was of medium-to-large magnitude $\left(r^{2}=0.092\right)$ : More than $9 \%$ of the variation in gamers' problem gambling was accounted for by measuring the extent to which they spent money on loot boxes.

This relationship seems reliable: all previous studies which have measured these variables have consistently reported its existence (e.g. [5], [6], [44], [55]). Its replication in a preregistered analysis also strongly suggests its robustness. Lending extra weight to the importance of this link is the effect size associated with this analysis. Previous estimates have placed this effect at approximately $\eta^{2}=$ 0.05. In this analysis we see an effect of almost double this size. This supports the importance of loot box spending as a potential risk factor for problem gambling.

In a similar vein, these results support $\mathbf{H 2}$ ("There will be a significant relationship between whether a player pays for loot boxes and their problem gambling"). When it came to our measure of problem gambling severity, individuals who paid for loot boxes scored more than twice as high, on average, than those who did not ( $M=2.190$ for those who did not pay, $M=5.407$ for those who did). 
When taken together, both the results of $\mathbf{H} \mathbf{1}$ and $\mathbf{H} \mathbf{2}$ strongly suggest that paying money for loot boxes is linked to problem gambling. The causal direction of this relationship is unclear. It may be the case that loot boxes share so many formal features with gambling that they act as a gateway to problem gambling itself. It may also be the case that loot boxes share so many formal features with gambling that they are particularly attractive to problem gamblers, leading individuals with higher levels of problem gambling to spend more money on them.

\section{The effects of cashing out}

H3-H6 tested whether being able to cash out loot box contents for real-world money strengthened links between loot box spending and problem gambling. Results of each of these tests indicated that the ability to cash out significantly strengthened links between loot box spending and problem gambling.

This might initially suggest that, as proposed in [3], loot boxes that feature cash out mechanisms may act as a uniquely strong 'gateway' to problem gambling. They therefore should be regulated above and beyond other loot boxes. However, caution is warranted when making this determination.

Whilst cash out did appear to strengthen links between loot box spending and problem gambling, it is key to note that this strengthening effect was of a very small magnitude: Between an $r^{2}$ change of 0.002 and 0.011 . In other words, when we incorporated this feature into our model of the effects of loot box spending on problem gambling, its moderating effect was only able to predict an additional $0.2 \%-1.1 \%$ of players problem gambling.

Furthermore, spotlight analyses for all hypothesis tests associated with cashing out revealed that loot box spending remained significantly linked $(p<0.001)$ to problem gambling, regardless of whether cash out was present or absent.

The effects of paying to win, near misses, and using in-game currency

H9-11 tested how a variety of features strengthened links between loot box spending and problem gambling: $\mathbf{H} \mathbf{9}$ tested the presence of pay to win features; $\mathbf{H 1 0}$ tested the presence of near misses; H11 tested the presence of in-game currency.

Just as with the presence of cash out, all of these features strengthened links between problem gambling and loot box spending. However, as with cash out, all of the effects associated with these moderators were of very small magnitude ( $\mathbf{H} \mathbf{9} \mathrm{r}^{2}$ change $=0.006 ; \mathbf{H 1 0} r^{2}$ change $=0.005 ; \mathbf{H 1 1} r^{2}$ change $=0.006$ ). Again, spotlight analyses revealed that loot box spending remained significantly linked to problem gambling $(p<0.001)$ regardless of the presence or absence of these variables.

These results suggest that regardless of the presence or absence of individual loot boxes features, spending money on them is linked to problem gambling.

The effects of crate and key mechanics and the presence of exclusive items

Neither crate and key mechanics nor the presence of exclusive items in loot boxes significantly strengthened links between loot box spending and problem gambling. This may be due to a number of factors: For example, it may be the case that the relatively scarce frequency of games that did not feature exclusive items (281 cases of 1172 total) meant that our analysis lacked the power to detect a subtle effect. Further work is necessary to determine whether this absence of an important effect is reliably observed. 
The relationship between problem gambling and selling loot box items for money

A final note must be made about $\mathbf{H 7}$, the hypothesis that the amount of money made by selling loot box items will strengthen the relationship between loot box spending and problem gambling. The more money players made, the more severe their gambling problems (H8). Furthermore, as shown in Table 4, the amount of money that players made by selling loot box items significantly moderated the relationship between loot box spending and problem gambling.

However, contrary to predictions, the more money an individual made selling loot box items, the weaker their relationship between loot box spending and problem gambling. It is not clear what this relationship indicates. It might indicate, for instance, the presence of a group of gamers who tactically buy specific kinds of loot boxes in order to sell their contents at a profit on external marketplaces. Further work is needed to determine whether this relationship is either robust or of practical importance.

\section{Relationship to previous literature}

Previous studies have reliably found a link between loot box spending and problem gambling. In [4], Macey and Hamari found a link between loot box spending and problem gambling in a sample of eSports spectators. In [5], Zendle and Cairns found a link between these variables in a large $(n=7,422)$ convenience sample of online gamers. The magnitude of this link was equivalent to of $r^{2}=$ 0.052 . They later replicated this link in a sample of gamers that did not self-select into a loot box study, and were unaware of the study's aims [6]. The magnitude of the link found in this replication study was equivalent to $r^{2}=0.051$

This preponderance of evidence suggests that the relationship between loot box spending and problem gambling is robust and reliable. It is important to note that the magnitude of the relationship seen here was relatively larger than the link seen in previous studies: $r^{2}=0.092$ as opposed to $r^{2} s$ of 0.052 or 0.051 . This suggests that the potential for harm present in loot boxes may be stronger than was previously thought.

How does this fit with previous work on the effects of video games? There is now a wide-ranging body of literature that investigates the potential effects of excessive gaming [56]. The World Health Organisation have recently included "Gaming Disorder" in the ICD-11's list of "disorders due to addictive behaviours" [57] and the APA have proposed to include "Internet Gaming Disorder" in the DSM-V[58]. These decisions bear testimony to how seriously policymakers and clinicians take excessive video game play. These classifications are controversial [59], [60]. However, it may be the case that there is a vulnerable group of gamers who engage in video game play in a disordered and excessive manner. One could speculate that, for such gamers, loot boxes may be especially problematic. Since these gamers are thought to invest inordinate time in gaming activities, they may also spend inordinate amounts of money on loot boxes. This speculation is supported by recent research conducted in [61], in which loot box spending was found to be linked to both problem gambling and disordered gaming behaviours.

This sort of study necessarily only reveals that there is relationship between lootbox spending and problem gambling. The next step would therefore be to begin to investigate how this relationship arises. The results suggest that the particular styles or mechanisms of lootboxes are of only incidental relevance to the relationship thus it seems sufficient in this context to take lootboxes as a single, unified feature of games. It is reasonable to presume that, for children who play games, lootboxes may be the first encounter with a gambling type mechanism. Pathways to problem gambling typically begin with access to some form of gambling [2]. Problem gambling careers may begin with recreational gambling activities before progressing to more problematic forms of 
gambling. For example, the transition from other forms of gambling to machine gambling has been associated with the onset of problem gambling [62]. Similarly, amongst adolescents, the path to problem gambling often begins with "gambling for free" before moving on to playing card games for money[63]. There is speculation in the literature that early exposure to relatively innocuous forms of gambling may introduce individuals to the exciting properties of gambling, and thus lead to engagement with more high-risk forms of gambling[64]. The results observed here may fit this pattern: If, as suggested by [3], some loot boxes are "psychologically akin" to gambling, then engagement with them may lead to engagement with other related activities, such as slot machines. From this progression, problem gambling behaviours may further develop.

A similar perspective may be drawn from the gambling literature regarding social casinos. There is evidence in the literature that spending money on these gambling-like experiences may lead individuals to engage in gambling [65]. This may be because exposure to experiences that appear similar to gambling leads to the promotion of biases regarding gambling, and may also lead to desensitisation to monetary losses[66]. These results also suggest that the psychological kinship between loot boxes and gambling may allow them to act as a gateway to gambling proper and hence, problem gambling. However, further work is necessary to determine the nature of links between disordered gaming, loot box spending, and gambling-related harm.

\section{Conclusions}

These analyses suggest that as long as they cost real-world money, loot boxes are not rendered harmless by removing any single feature.

Our preregistered analyses of $\mathbf{H 1}-\mathbf{H} \mathbf{2}$ show that the more gamers spend on loot boxes, the more severe their problem gambling. Furthermore, gamers who paid for loot boxes (rather than engaging solely in unpaid openings) scored more than twice as high on measures of problem gambling than those who did not.

Further preregistered analyses painted an even starker picture. Regardless of the individual features of loot boxes themselves, the link between spending money on them and problem gambling remains. Regardless of whether or not loot boxes gave players gameplay advantages, allowed them to trade items for real world money, allowed them to cash-out, or showed near-misses, we still observed a link between loot box spending and problem gambling. Omitting any of these features did not cause this link to disappear. We therefore find no evidence to support the argument that any specific type of loot box is harmless.

When taken together, both the results of these tests strongly suggest that paying money for loot boxes is linked to problem gambling.

However, it is important to note that the specific meaning of this link is unclear. It may be the case that it represents a relationship in which exposure to loot boxes leads to a greater proportion of gamers engaging in gambling activities outside of games. This greater involvement in gambling would naturally lead to a higher severity of problem gambling amongst loot box-buying gamers. Thus, loot box spending leads to gambling, which in turn leads to problem gambling. This explanation would be consonant with theories like Blaszczynski and Nower's pathways model [2], which suggests that the first step along a path to problem gambling is often the increased availability of gambling. 
Alternatively, another causal relationship entirely may occur: In [3], Drummond and Sauer note that loot boxes share a variety of formal features with gambling. It may be the case that they share so many of these features that they are rendered particularly attractive to problem gamblers, who are characterised by their disordered and excessive involvement in gambling activities. In this case, loot boxes would not be linked to problem gambling because they provide a 'gateway' to problem gambling, but rather because loot boxes capitalize on problem gamblers' self-destructive behaviour.

It may even be the case that all of the relationships outlined above are simultaneously true: Loot box spending leads to both the development of biased cognitive schemas and increases in gambling activity. Increases in gambling activity, in turn, simultaneously cause individuals to spend more money on loot boxes. Significant clinical, longitudinal, and experimental work is necessary to determine the nature of the relationship between loot box spending and problem gambling.

Loot boxes may make up to $\$ 30$ billion this year alone [1]. It is unclear what the social cost of this profit may be, and further work is necessary to determine the exact nature of links between loot box spending and problem gambling. The evidence contained in this study suggests that regardless of the features of loot boxes, if players pay money for them then they are linked in some way to problem gambling. It is unclear whether this link represents a situation in which loot boxes literally cause problem gambling, or whether they represent a situation in which problem gamblers spend significantly larger amounts of money on loot boxes.

Regardless, given the potential for harm that is present here, agencies that are responsible for determining ratings and classifications of video games, like PEGI and the ESRB, might consider the inclusion of content descriptors that are specific to loot boxes. This would enable consumers to make more informed decisions about whether to buy products that contain loot boxes. Ratings agencies might also consider restricting access to games with paid loot boxes to players who are of legal gambling age. 


\section{Bibliography}

[1] Juniper Research, "In-Game Gambling The Next Cash Cow for Publishers," Apr2018. [Online]. Available: https://www.juniperresearch.com/document-library/whitepapers/in-game-gambling- -the-next-cash-cow. [Accessed: 15-Jul-2018].

[2] A. Blaszczynski and L. Nower, "A pathways model of problem and pathological gambling," Addiction, vol. 97, no. 5, pp. 487-499, 2002.

[3] A. Drummond and J. D. Sauer, "Video game loot boxes are psychologically akin to gambling," Nat. Hum. Behav., pp. 530-532, Jun. 2018.

[4] J. Macey and J. Hamari, "eSports, skins and loot boxes: Participants, practices and problematic behaviour associated with emergent forms of gambling," New Media Soc., p. 1461444818786216, Jul. 2018.

[5] D. Zendle and P. Cairns, "Video game loot boxes are linked to problem gambling: Results of a large-scale survey," PLoS One, vol. 13, no. 11, p. e0206767, 2018.

[6] D. Zendle and P. Cairns, "Loot boxes are again linked to problem gambling: Results of a replication study," PLoS One, vol. 14, no. 3, p. e0213194, Mar. 2019.

[7] L. Lanier and L. Lanier, "Sixteen European, US Gambling Regulators Teaming Up to Tackle Loot Boxes, Skin Gambling," Variety, 17-Sep-2018. .

[8] "Finland Begins Investigating Loot Box Practices," Gaming News, Reviews, and Articles - TechRaptor.net, 16-Sep-2018. .

[9] M. Kelly, "FTC to hold a public workshop on loot box concerns this year," The Verge, 22-Feb-2019. [Online]. Available:

https://www.theverge.com/2019/2/22/18236352/loot-box-video-game-ftc-workshop-hassancongress. [Accessed: 05-Mar-2019].

[10] L. Postrado, "Legal definition saves loot boxes from gambling classification in France," CalvinAyre.com, 05-Jul-2018. [Online]. Available:

https://calvinayre.com/2018/07/05/business/legal-definition-saves-loot-boxes-gamblingclassification-france/. [Accessed: 12-Aug-2018].

[11] W. Usher, "CS: GO Players In Belgium And The Netherlands Can No Longer Open Loot Boxes,” CINEMABLEND, 15-Jul-2018. [Online]. Available:

https://www.cinemablend.com/games/2450129/cs-go-players-in-belgium-and-thenetherlands-can-no-longer-open-loot-boxes. [Accessed: 12-Aug-2018].

[12] Australian Senate Standing Committee on Envirionment and Communications, "Transcript of Environment and Communications References Committee : 17/09/2018 : Gaming microtransactions for chance based items," 17-Sep-2018. [Online]. Available: https://parlinfo.aph.gov.au/parlInfo/search/display/display.w3p;query=Id:\%22committees/co mmsen/6d50090a-f828-4a8f-a1a8-81bbada6a513/0000\%22. [Accessed: 26-Oct-2018].

[13] H. Cryer, "Overwatch How to Earn Loot Boxes Guide - Emotes, Sprays, Legendary Skins," USgamer, 09-Aug-2017. . 
[14] "Clash Royale Chest Guide: How To Get Super Magical, Gold And Crown Chests For More Gems, Gold And Cards," Player.One, 10-Mar-2016. [Online]. Available:

https://www.player.one/clash-royale-chest-guide-how-get-super-magical-gold-and-crownchests-more-gems-gold-518292. [Accessed: 10-Oct-2018].

[15] “Hextech Crafting Guide," Riot Games Support. [Online]. Available:

http://support.riotgames.com/hc/en-us/articles/207884233-Hextech-Crafting-Guide. [Accessed: 10-Oct-2018].

[16] M. Kim, "Star Wars Battlefront 2 Will Completely Remove Paid Loot Crates and Star Cards," USgamer, 16-Mar-2018. .

[17] M. D. Griffiths, "Is the buying of loot boxes in video games a form of gambling or gaming?," Gaming Law Rev., vol. 22, no. 1, pp. 52-54, 2018.

[18] S. Coutu, "Here's How You Make \$12,000 In Profit a Day Selling Virtual Guns," Motherboard, 30-Jun-2015. .

[19] L. N. R. Kristian and G. Paweł, "Are Loot Boxes Gambling? Random reward mechanisms in video games," 2018.

[20] W. Yin-Poole, "The Netherlands declares some loot boxes are gambling," Eurogamer, 19-Apr-2018. .

[21] J. C. Mowen, X. Fang, and K. Scott, "A hierarchical model approach for identifying the trait antecedents of general gambling propensity and of four gambling-related genres," $J$. Bus. Res., vol. 62, no. 12, pp. 1262-1268, 2009.

[22] J. C. Mowen, "Exploring the trait of competitiveness and its consumer behavior consequences," J. Consum. Psychol., vol. 14, no. 1-2, pp. 52-63, 2004.

[23] A. Parke, M. Griffiths, and P. Irwing, "Personality traits in pathological gambling: Sensation seeking, deferment of gratification and competitiveness as risk factors," Addict. Res. Theory, vol. 12, no. 3, pp. 201-212, 2004.

[24] P. Raghubir and J. Srivastava, "Monopoly money: The effect of payment coupling and form on spending behavior.," J. Exp. Psychol. Appl., vol. 14, no. 3, p. 213, 2008.

[25] J. Lapuz and M. D. Griffiths, "The role of chips in poker gambling: An empirical pilot study," Gambl. Res. J. Natl. Assoc. Gambl. Stud. Aust., vol. 22, no. 1, p. 34, 2010.

[26] H. R. Arkes and C. Blumer, "The psychology of sunk cost," Organ. Behav. Hum. Decis. Process., vol. 35, no. 1, pp. 124-140, 1985.

[27] M. Griffiths and R. Wood, "The psychology of lottery gambling," Int. Gambl. Stud., vol. 1, no. 1, pp. 27-45, 2001.

[28] H. Rachlin, "Why do people gamble and keep gambling despite heavy losses?," Psychol. Sci., vol. 1, no. 5, pp. 294-297, 1990.

[29] E. J. Langer, "The illusion of control.," J. Pers. Soc. Psychol., vol. 32, no. 2, p. 311, 1975. 
[30] L. Clark, "Decision-making during gambling: an integration of cognitive and psychobiological approaches," Philos. Trans. R. Soc. Lond. B Biol. Sci., vol. 365, no. 1538, pp. 319-330, 2010.

[31] T. Toneatto, T. Blitz-Miller, K. Calderwood, R. Dragonetti, and A. Tsanos, "Cognitive Distortions in Heavy Gambling," J. Gambl. Stud., vol. 13, no. 3, pp. 253-266, Sep. 1997.

[32] M. Griffiths, "Fruit machine gambling: The importance of structural characteristics," J. Gambl. Stud., vol. 9, no. 2, pp. 101-120, 1993.

[33] N. D. Schüll, Addiction by Design: Machine Gambling in Las Vegas. Princeton University Press, 2012.

[34] R. L. Reid, "The psychology of the near miss," J. Gambl. Behav., vol. 2, no. 1, pp. 32-39, 1986.

[35] D. Côté, A. Caron, J. Aubert, V. Desrochers, and R. Ladouceur, "Near wins prolong gambling on a video lottery terminal," J. Gambl. Stud., vol. 19, no. 4, pp. 433-438, 2003.

[36] L. H. Strickland and F. W. Grote, "Temporal presentation of winning symbols and slot-machine playing.," J. Exp. Psychol., vol. 74, no. 1, p. 10, 1967.

[37] M. Griffiths, "Gambling technologies: Prospects for problem gambling," J. Gambl. Stud., vol. 15, no. 3, pp. 265-283, 1999.

[38] J. A. Ferris and H. J. Wynne, The Canadian problem gambling index. Canadian Centre on Substance Abuse Ottawa, ON, 2001.

[39] N. R. Council, Pathological gambling: A critical review. National Academies Press, 1999.

[40] M. Griffiths, "Betting your life on it," $B M J$, vol. 329, no. 7474, pp. 1055-1056, Nov. 2004.

[41] R. G. Kalischuk, N. Nowatzki, K. Cardwell, K. Klein, and J. Solowoniuk, "Problem Gambling and its Impact on Families: A Literature Review," Int. Gambl. Stud., vol. 6, no. 1, pp. 31-60, Jun. 2006.

[42] J. L. McComb, B. K. Lee, and D. H. Sprenkle, "Conceptualizing and treating problem gambling as a family issue,” J. Marital Fam. Ther., vol. 35, no. 4, pp. 415-431, 2009.

[43] Y. Komoto, "Factors associated with suicide and bankruptcy in Japanese pathological gamblers," Int. J. Ment. Health Addict., vol. 12, no. 5, pp. 600-606, 2014.

[44] Zendle David, Meyer Rachel, and Over Harriet, "Adolescents and loot boxes: links with problem gambling and motivations for purchase," R. Soc. Open Sci., vol. 6, no. 6, p. 190049, Jun. 2019.

[45] S. R. Currie, D. C. Hodgins, and D. M. Casey, "Validity of the problem gambling severity index interpretive categories," J. Gambl. Stud., vol. 29, no. 2, pp. 311-327, 2013. 
[46] J. Orford, H. Wardle, M. Griffiths, K. Sproston, and B. Erens, "PGSI and DSM-IV in the 2007 British Gambling Prevalence Survey: reliability, item response, factor structure and inter-scale agreement," Int. Gambl. Stud., vol. 10, no. 1, pp. 31-44, Apr. 2010.

[47] T. Holtgraves, "Evaluating the Problem Gambling Severity Index," J. Gambl. Stud., vol. 25, no. 1, p. 105, Aug. 2008.

[48] M. J. Dixon, C. Graydon, K. A. Harrigan, L. Wojtowicz, V. Siu, and J. A. Fugelsang, "The allure of multi-line games in modern slot machines," Addiction, vol. 109, no. 11, pp. 1920-1928, 2014.

[49] L. Quigley et al., "Comorbid problem gambling and major depression in a community sample,” J. Gambl. Stud., vol. 31, no. 4, pp. 1135-1152, 2015.

[50] J. D. Edgerton, T. S. Melnyk, and L. W. Roberts, "Problem gambling and the youthto-adulthood transition: assessing problem gambling severity trajectories in a sample of young adults," J. Gambl. Stud., vol. 31, no. 4, pp. 1463-1485, 2015.

[51] "Not all loot boxes are created equal," OSF, Oct. 2018.

[52] D. Zendle, "Survey on features of loot boxes," 2018. [Online]. Available:

https://yorksj.eu.qualtrics.com/jfe/form/SV_d6vX0Yty85iBwJ7. [Accessed: 22-Apr-2019].

[53] A. F. Hayes, Introduction to Mediation, Moderation, and Conditional Process Analysis, Second Edition: A Regression-Based Approach. Guilford Publications, 2017.

[54] D. Zendle and P. Cairns, "OSF Data Repository for 'Loot boxes are again linked to problem gambling: Results of a replication study,", Sep. 2018.

[55] J. Macey and J. Hamari, "Investigating relationships between video gaming, spectating esports, and gambling," Comput. Hum. Behav., vol. 80, pp. 344-353, Mar. 2018.

[56] F. W. Paulus, S. Ohmann, A. Von Gontard, and C. Popow, "Internet gaming disorder in children and adolescents: a systematic review," Dev. Med. Child Neurol., vol. 60, no. 7, pp. 645-659, 2018.

[57] G. M. Reed et al., "Innovations and changes in the ICD-11 classification of mental, behavioural and neurodevelopmental disorders," World Psychiatry, vol. 18, no. 1, pp. 3-19, 2019.

[58] D. J. Kuss, M. D. Griffiths, and H. M. Pontes, "Chaos and confusion in DSM-5 diagnosis of Internet Gaming Disorder: Issues, concerns, and recommendations for clarity in the field," J. Behav. Addict., vol. 6, no. 2, pp. 103-109, 2017.

[59] A. K. Przybylski, N. Weinstein, and K. Murayama, "Internet gaming disorder: Investigating the clinical relevance of a new phenomenon," Am. J. Psychiatry, vol. 174, no. 3, pp. 230-236, 2016.

[60] E. Aarseth et al., "Scholars' open debate paper on the World Health Organization ICD-11 Gaming Disorder proposal," J. Behav. Addict., vol. 6, no. 3, pp. 267-270, 2017.

[61] W. Li, D. Mills, and L. Nower, "The relationship of loot box purchases to problem video gaming and problem gambling," Addict. Behav., vol. 97, pp. 27-34, Oct. 2019. 
[62] G. Reith and F. Dobbie, "Gambling careers: A longitudinal, qualitative study of gambling behaviour,” Addict. Res. Theory, vol. 21, no. 5, pp. 376-390, 2013.

[63] R. A. Volberg, E. C. Hedberg, and T. L. Moore, "Oregon youth and their parents: Gambling and problem gambling prevalence and attitudes," Oregon Department of Human Services, 2008.

[64] J. Felsher, J. Derevensky, and R. Gupta, "Lottery participation by youth with gambling problems: Are lottery tickets a gateway to other gambling venues?," Int. Gambl. Stud., vol. 4, no. 2, pp. 109-125, 2004.

[65] H. S. Kim, M. J. A. Wohl, M. M. Salmon, R. Gupta, and J. Derevensky, "Do Social Casino Gamers Migrate to Online Gambling? An Assessment of Migration Rate and Potential Predictors," J. Gambl. Stud., vol. 31, no. 4, pp. 1819-1831, Dec. 2015.

[66] T. Armstrong, M. Rockloff, M. Browne, and E. Li, “An Exploration of How Simulated Gambling Games May Promote Gambling with Money," J. Gambl. Stud., vol. 34, no. 4, pp. 1165-1184, Dec. 2018. 